through the third intercostal space. The device was covered with a polytetrafluoroethylene (Gore-Tex) mesh to minimize lung adhesions.

For 7 cases, bypass times ranged from 68 to 136 minutes. Intraoperative blood product use ranged from 0 to 3 units of red blood cells, 2 to 3 units of fresh frozen plasma, and 1 to 2 pooled platelet units. Preoperatively, all patients had at least moderate RV dysfunction determined by cardiac magnetic resonance imaging (RV ejection fraction range, 20\%$35 \%$ ). Yet, postoperative RV failure did not develop in any of the patients. Four patients were extubated between 12 and 24 hours after surgery. The other 3 patients were extubated on postoperative days 2,5 , and 7 .

\section{DISCUSSION}

As LVAD support for patients with heart failure becomes increasingly popular, concern for redo sternotomies increases. ${ }^{4}$ Further, reoperative sternotomy at the time of subsequent heart transplantation has been associated with decreased short- and long-term survival. To avoid redo sternotomy, new methods of LVAD implantation must be explored, particularly as new-generation devices become smaller and more conducive to minimally invasive implantation. Our approach improves on existing less-invasive approaches for LVAD implantation because robotic technology provides optimal visualization for RV dissection and reduced risk of kinking the outflow graft. ${ }^{5}$ Performing the anastomosis of the graft to the ascending aorta through right chest ports further decreases mediastinal dissection. This may improve outcomes in these patients at the time of transplantation. Furthermore, the robotic ports discussed are suitable for concomitant procedures usually performed through the right chest.

\section{CONCLUSIONS}

Refinements in surgical technique, team development and training methods, and patient selection and management will enable robotic technology to play an important role in LVAD implantation.

The authors thank Katherine Stavoe and Kitsie Penick for assistance with article preparation and Rita Ellsworth for developing the figures.

\section{References}

1. Rose EA, Gelijns AC, Moskowitz AJ, Heitjan DF, Stevenson LW, Dembitsky W, et al. Randomized Evaluation of Mechanical Assistance for the Treatment of Congestive Heart Failure (REMATCH) Study Group. Long-term use of a left ventricular assist device for end-stage heart failure. $N$ Engl J Med. 2001;345: $1435-43$.

2. George TJ, Beaty CA, Ewald GA, Russell SD, Shah AS, Conte JV, et al Reoperative sternotomy is associated with increased mortality after heart transplantation. Ann Thorac Surg. 2012;94:2025-32.

3. Park CB, Suri RM, Burkhart HM, Greason KL, Dearani JA, Schaff HV, et al Identifying patients at particular risk of injury during repeat sternotomy: analysis of 2555 cardiac reoperations. J Thorac Cardiovasc Surg. 2010;140: 1028-35.

4. Kamdar F, John R, Eckman P, Colvin-Adams M, Shumway SJ, Liao K Postcardiac transplant survival in the current era in patients receiving continuous-flow left ventricular assist devices. J Thorac Cardiovasc Surg. 2013; 145:575-81.

5. Cheung A, Lamarche Y, Kaan A, Munt B, Doyle A, Bashir J, et al. Off-pump implantation of the HeartWare HVAD left ventricular assist device through minimally invasive incisions. Ann Thorac Surg. 2011;91:1294-6.

\title{
Left atrial pressure monitoring in patients with a HeartMate II device using a Codman Microsensor
}

\author{
Igor Gosev, MD, Leacche Marzia, MD, Robert C. Neely, MD, and Gregory S. Couper, MD, Boston, Mass
}

Ventricular assist devices have become an important element for the treatment of advanced heart failure. ${ }^{1}$ Since 2006, more than 6000 mechanical assist devices have been implanted in patients in the United States. ${ }^{2}$ In 2008, the

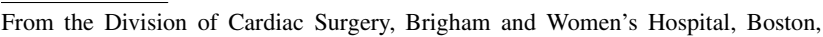
Mass.

Disclosures: Authors have nothing to disclose with regard to commercial support. Received for publication Aug 8, 2013; revisions received Nov 29, 2013; accepted for publication Dec 10, 2013; available ahead of print Jan 10, 2014.

Address for reprints: Igor Gosev, MD, Division of Cardiac Surgery, Brigham and Women's

Hospital, 75 Frances St, Boston, MA 02115 (E-mail: igosev@ partners.org).

J Thorac Cardiovasc Surg 2014;147:1425-7

$0022-5223 / \$ 36.00$

Copyright (c) 2014 by The American Association for Thoracic Surgery

http://dx.doi.org/10.1016/j.jtcvs.2013.12.003
}

second-generation axial flow HeartMate II (Thoratec Corp, Pleasanton, Calif) pump was approved by the Food and Drug Administration as a bridge to transplant therapy

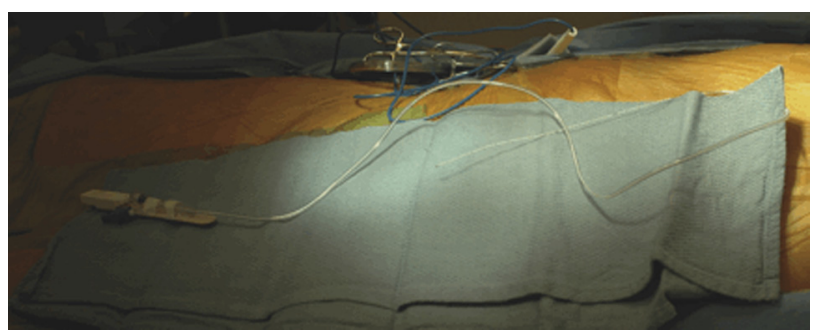

FIGURE 1. Assembled left atrial line. 


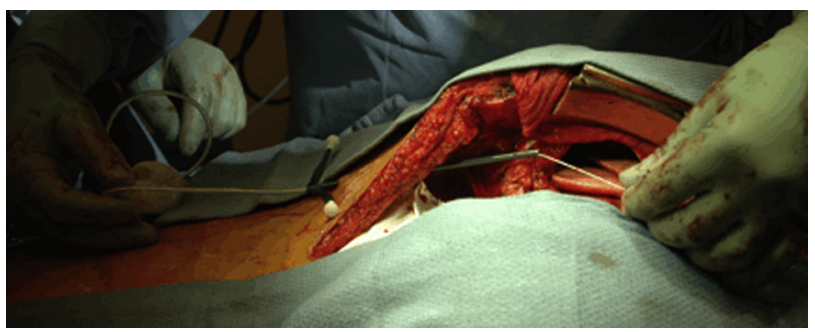

FIGURE 2. Placement of the left atrial line through the abdominal wall.

and in 2010 as a destination therapy for patients not eligible for heart transplantation. ${ }^{3,4}$

\section{CLINICAL SUMMARY}

Successful early and late survival depend on multiple perioperative factors. Accurate measurement of preload to the right ventricle and left ventricle (LV) is one of the main parameters that guide therapy in the early postoperative course. Right-sided heart failure can occur during significant unloading of the LV with the HeartMate II device because of an intraventricular septal shift to the left in systole and decreased right ventricular output. ${ }^{5}$ Thus, accurate and preferably continuous assessments of right atrial (RA) and left atrial (LA) pressures are extremely important.

RA pressure is obtained from the central venous line placed in the right atrium or from the RA port of the Swan-Ganz catheter. LA pressure may be indirectly estimated using pulmonary artery diastolic pressure, but this method may be inaccurate in the presence of increased pulmonary vascular resistance. ${ }^{6}$ Using pulmonary capillary wedge pressure as a surrogate for LA pressure is more labor-intensive and yields only intermittent values. Direct measurement of LA pressure with regular fluid-filled pressure tubing used on the right side is reliable but carries the risk of air embolism or bleeding during removal.

We describe a novel way of directly measuring LA pressure using a Codman Microsensor (DePuy Co, Raynham, Mass) and pressure wire, a technique routinely used for measuring intracranial pressure.

Between February 2010 and December 2012 at Brigham and Women's Hospital, 61 patients underwent implantation of the HeartMate II device with the concomitant use of a

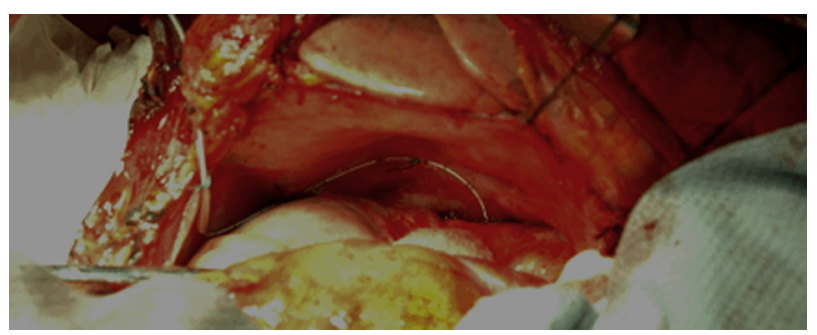

FIGURE 3. Position of the left atrial line within the pericardium.

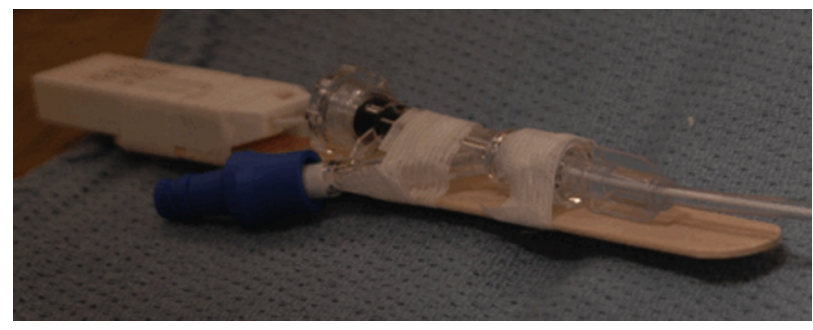

FIGURE 4. Microsensor transducer passed through a $5 \mathrm{~F}$ guiding catheter and secured with a rotating hemostatic valve.

Codman LA pressure monitoring system. After partial division of the left diaphragm and formation of the HeartMate II device pocket and before heparinization and cardiopulmonary bypass initiation, a pledgeted Ethibond (Ethicon, Somerville, NJ) 2-0 mattress suture is placed in the right superior pulmonary vein. An LA pressure catheter is then inserted in the same fashion as fluid-filled catheters, except a critical step of zeroing the Microsensor transducer is done before insertion. During the preparation for insertion, a Microsensor transducer is passed through a $5 \mathrm{~F}$ guiding catheter and secured with a rotating hemostatic valve. The catheter is passed through the abdominal wall, zeroed, and then inserted into the LA through the madras suture that is secured around the catheter, but not too tight so it can be pulled out. The catheter is then stabilized using multiple Vicryl sutures to the right pericardium to minimize dislodgment. Silk sutures are placed to secure the catheter at the skin exit site (Figures 1-5).

Initial LA pressure is recorded together with the preimplantation right-sided filling pressures (Figure 6). After implantation of the HeartMate II device and during cardiopulmonary bypass weaning, correlation of the LA pressure and the LV unloading to the intraventricular septal dynamics on transesophageal echocardiography for a specific HeartMate II device speed is closely monitored. A range of wanted LA pressures is then recorded, and the patient is weaned from cardiopulmonary bypass.

In the intensive care unit, the desired range of LA pressures established in the operating room is one of the main hemodynamic parameters guiding therapy. Between postoperative days 2 and 5 and after stabilization of the patient's hemodynamics, the LA pressure line is taken out. Safe removal requires stable coagulation parameters and

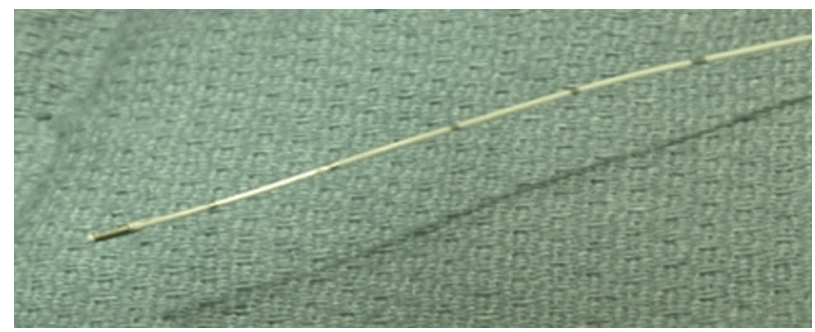

FIGURE 5. Tip of the Codman Microsensor (DePuy Co, Raynham, Mass). 


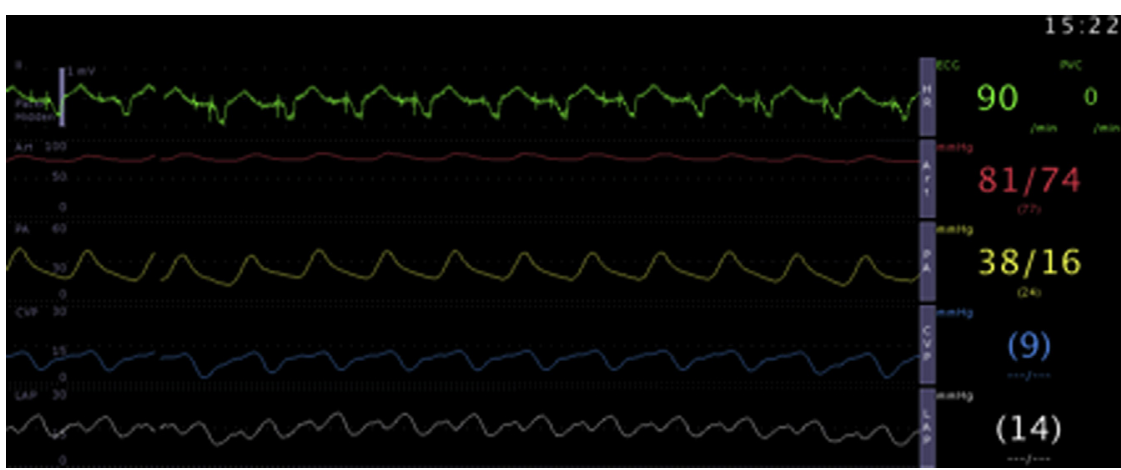

FIGURE 6. Left atrial line waveform (bottom, white).

temporary increase in HeartMate II device flows to decrease LA pressure and minimize bleeding into the pericardial cavity. Early in our series, we had the tip of the catheter dislodged in the pericardial cavity in 2 patients and 1 patient had a suction event after pre-pull HeartMate II device speed adjustment emptied the LV. After these initial complications, we used guide catheters to prevent dislodgement of the sensor tip. No bleeding or systemic embolic complications related to this LA monitoring system have been noted in our series.

\section{CONCLUSIONS}

Our off-label LA pressure monitoring system using a Codman Microsensor offers safe and reliable results with minimal or no complications and should be implanted in all patients requiring direct LA pressure monitoring.

\section{References}

1. Rose EA, Gelijns AC, Moskowitz AJ, Heitjan DF, Stevenson LW, Dembitsky W, et al. Long-term use of a left ventricular assist device for end-stage heart failure. N Engl J Med. 2001;345:1435-43.

2. Kirklin JK, Naftel DC, Kormos RL, Stevenson LW, Pagani FD, Miller MA, et al The Fifth INTERMACS Annual Report: risk factor analysis from more than 6,000 mechanical circulatory support patients. J Heart Lung Transplant. 2013;32: 141-56.

3. Miller LW, Pagani FD, Russell SD, John R, Boyle AJ, Aaronson KD, et al. Use of continuous-flow device in patients awaiting heart transplantation. $N$ Engl J Med. 2007:357:885-96.

4. Slaughter MS, Rogers JG, Milano CA, Russell SD, Conte JV, Feldman D, et al Advanced heart failure treated with continuous-flow left ventricular assist device. N Engl J Med. 2009;361:2241-51.

5. Kormos RL, Teuteberg JJ, Pagani FD, Russell SD, John R, Miller LW, et al Right ventricular failure in patients with the HeartMate II continuous-flow left ventricular assist device: incidence, risk factors, and effect on outcomes. J Thorac Cardiovasc Surg. 2010;139:1316-24

6. Jenkins BS, Bradley RD, Branthwaite MA. Evaluation of pulmonary arterial end-diastolic pressure as an indirect estimate of left atrial mean pressure. Circulation. 1970;42:75-8

\title{
A technique for repair of partial anomalous pulmonary vein connection to the superior vena cava
}

\author{
José Pedro da Silva, MD, ${ }^{\mathrm{a}}$ Luciana da Fonseca da Silva, MD, ${ }^{\mathrm{a}, \mathrm{b}}$ Cintia Acosta Melo, MD, ${ }^{\mathrm{a}}$ and \\ Lilian Maria Lopes, MD, ${ }^{\mathrm{a}}$ São Paulo, Brazil
}

The repair of a partial anomalous pulmonary venous connection (PAPVC) to the high superior vena cava

\footnotetext{
From the Cardiac Surgery Division, ${ }^{\mathrm{a}}$ Hospital Beneficencia Portuguesa de São Paulo, São Paulo, São Paulo, Brazil; and Federal University of Sao Paulo State Medical School, ${ }^{\mathrm{b}}$ São Paulo, São Paulo, Brazil.

Disclosures: Authors have nothing to disclose with regard to commercial support.

Received for publication Oct 31, 2013; revisions received Nov 30, 2013; accepted for publication Dec 12, 2013; available ahead of print Jan 31, 2014.

Address for reprints: José Pedro da Silva, MD, Cardiac Surgery Division, Hospital Beneficencia Portuguesa de São Paulo, Rua Maestro Cardim, 769, Sala 202, São Paulo, SP 01323-900 Brazil (E-mail: dasilvajp@uol.com.br).

J Thorac Cardiovasc Surg 2014;147:1427-9

$0022-5223 / \$ 36.00$

Copyright (C) 2014 by The American Association for Thoracic Surgery

http://dx.doi.org/10.1016/j.jtcvs.2013.12.014
}

(SVC) was simplified by the surgical procedure reported by Warden et $\mathrm{al}^{1}$ in 1984 . They described a technique that consisted of dividing the SVC right above the anomalous pulmonary vein, oversewing the lower SVC end, connecting the SVC upper end to the right atrial appendage, and placing an intra-atrial patch to complete the pulmonary vein drainage to the left atrium through the atrial septal defect. This ingenious Warden procedure prevents damage to the sinus node and allows the involved anatomic structures to grow. However, this operation has a limitation for patients with a very high connection of the anomalous pulmonary vein to the SVC. In such situations, the caval division above the pulmonary vein entrance in the SVC 